\title{
Empirical Study on Ecological Niche Evaluation on Regional Construction Industry in China
}

\author{
Yousong Wang, Yufan Zhang*, Yang Li, Martin H. Asare and Yan Zhang \\ School of Civil Engineering and Transportation, South China University of Technology, Guangzhou, Guangdong, \\ 510640, China
}

\begin{abstract}
The ecological system of the construction industry had been divided into three aspects, i.e. economy, scale and technology. Basing on the ecological niche theory, this paper established the evaluation model and studied on the ecological niche status about national regional construction industry in China using statistical data from 2007 to 2012 . The analysis results show that Jiangsu, Zhejiang and Liaoning have the highest scores in the economic and the scaled niche. Tianjin, Beijing and Jiangsu's technology niche are better. Overall, Integrated niche still has a better performance in Jiangsu, Zhejiang and Liaoning. The calculated values are $0.1002,0.0696$ and 0.0592 respectively. In terms of the discreteness and the diversity, the score of the scaled niche is the highest. The economic niche's score is the second. And the lowest score is belonged to the technology niche. It is also found that the national construction industry has an unbalanced development in each area. The construction industry depends on the advantage of the economic investment and scaled advantage in the eastern coastal and the central regions. The level of the management and the technology is still low in the whole industry. Therefore, it is suggested that the Chinese government should enhance the strength of the construction investment and development in the north and west regions, ensuring the good developmental situation in the eastern and central regions. The $\mathrm{R} \& \mathrm{D}$ and the spreading of the technological advanced achievement should be strengthened. And the management and the technology level of the construction industry should be improved.
\end{abstract}

Keywords: construction industry, ecological niche, economy, scale, technology.

\section{INTRODUCTION}

As one of the basic theories belonged to the ecological theory, the niche theory has been widely used in the field of ecology. With the continuous development of the niche concept, ecological niche theory is being gradually expanded to the non-biological entity system areas such as economics, urban science, etc. Recognizing the construction industry as the entire ecosystem, we studied its ecological units' adaptability in the overall development of the environment and their current competitive advantage. And then this study offers a new research idea for related topics, like understanding the development of the regional construction industry, studying the comprehensive competitiveness for the regional construction industry. In this paper, the ecological niche of the national regional construction industry is estimated and evaluated basing on the ecological niche theory. Some suggestions on enhancing the competitiveness of the regional construction industry and realizing healthy and rapid development of the national construction industry were given.

\section{LITERATURE REVIEW}

Construction industry is a manufacturing industry, which is specialized in civil engineering, housing construction, equipment installation and engineering survey and design,

*Address correspondence to this author at the School of Civil Engineering and Transportation, South China University of Technology, Guangzhou, Guangdong, 510640, China; Tel: (86+)15602220188;

E-mail: zhangyufanchn@163.com etc. It is an important industrial department of the national economy. Its healthy development is related to the progress of the national economy, while it also has close contact with the improvement of the people's living standards. With the national fixed asset investment rate increased year by year, the gross product of construction industry accounted for the GDP has increased from $9.65 \%$ in 1994 to $26.41 \%$ in 2012. And the average annual growth rate of the total pre-tax profits is up to $24.69 \%$.

Nowadays, the construction industry showed a good state, including the constantly improved construction level, continually optimized industrial structure, stably promoted technical progress and gradually formed construction system. However, in the process of its development, some problems are also exposed, like the large difference of regional development, the strong dependence of investment, the low utility ratio of technical promotion, etc. These problems have attracted the attention of the scholars all over the world. The development of the whole construction industry determines the macro environment of the regional construction industry. Currently, the basic ways of understanding the macro situation and predicting the future tend about the construction industry are the comprehensive statistical analysis on the related indicators such as the gross product, the added gross product, etc $[1,2]$. Of course, the econometric analysis about the production efficiency and the production factors by using some mathematical models is also an effective way to understating the status of the construction industry $[3,4]$. The reformatory road of the national construction industry can be predicted though comparing with the developmental level of 
the developed countries [5]. In addition, the development of the regional construction industry is the foundation of the whole construction industry. Using relevant theory and software programming to analyze the developmental status from itself factors of the regional construction industry occupies the mainstream [6]. There are a few studies drawing a conclusion that the development of the regional construction industry not only was confined to its own factors, but also had a strong link with the some environmental factors like the geographic location, the industrial distribution, etc [7]. These own and environmental factors eventually lead to the differences in the regional development. The researches on the existence and the change about these differences directly affect the future strategic decision of the national overall construction [8]. The differences in regional development reflect the differences in the construction competitiveness. Therefore, scholars also have become very interested in the competitiveness and the competition efficiency of the regional construction industry. They have made a lot of empirical researches on the competitiveness and the competition efficiency of the regional construction industry by using different mathematical models $[9,10]$. Under the comprehensive action of the various factors, the specific structure of the project contracting market has been formed in each region. The measurement and the study on the regional market structure cannot be ignored [11]. With the speeding-up of the economic globalization, the impact on the local contracting market will gradually increase because of the foreign contractors' accessing [12]. In the new situation, the study on the development of the regional construction industry not only must be started from the aspect of the industry itself, but also should be comprehensively considered the impact of the exterior environment and the outside force.

Thus, the researches on the construction industry were not only widely coverage, but also done by many methods. It is worth mentioning that the ecological niche theory is mainly applied to the study of biology and urban comprehensive level. But so far, the study on the regional construction industry development is relatively rare from the perspective of the ecological niche theory. Therefore, this paper tries to analyze the ecological niche of the regional construction industry in the 31 provinces of china. It masters the development condition on the regional construction industry from a new angle.

\section{THEORIES AND ECONOMETRIC MODEL}

$\mathrm{J} \cdot$ Grinne put forward the concept of ecological niche in 1917 , which was confined to the biology field in the early days. He thought that the ecological niche was a basic unit occupied by a species or a subspecies, or their status and functions in the biomes. After continuous development, the ecological niche theory has been gradually applied to other disciplines. It is a worth topic to deeply discuss that the ecological niche theory is used to evaluate the development of the construction industry. Basing on the previous researches, the construction industry is regarded as the combination of the three elements (economy, scale and technology) in this paper. The ecological niche of the construction industry mainly embodies in two aspects: one is the advantages and disadvantages of these elements; the other is the status and the function of the combination in the whole system.
The ecological unit has two basic attributes in the ecological niche theory: the status and the tendency. "Status" refers to the condition of the ecological unit's development. It shows the results of the growth, the development and the interaction with the environment about the ecological unit, for instance, quantity of resources occupied, degree of economic development, etc. "Tendency" refers to the trend of the ecological unit's development. It reflects the real influence and domination from that the ecological unit exerts on the environment, such as conversion rate of the energy, growth rate of the material, etc. "Status" and "Tendency" jointly reflect the breadth of the ecological niche about the unit, i.e. the size of the ecological niche. According to the principle of the ecological niche theory, the larger the value of the ecological niche is, the wider its breadth is. It indicates that this ecological unit plays a more important role and has a greater competition in the whole ecological system. Otherwise, it is less important and has smaller impact on the surrounding environment [13].

The econometric model of the ecological niche with single factor is as follows:

$$
\begin{aligned}
& F_{i j}=\left(S_{i j}+D_{i j} P_{i j}\right) / \sum_{j=1}^{m}\left(S_{i j}+D_{i j} P_{i j}\right) \\
& E_{j}=\sum_{i=1}^{n} F_{i j} / n \\
& C_{i j}=\sqrt{\sum_{i=1}^{n}\left(N_{i j}+\bar{N}\right)^{2}} / n
\end{aligned}
$$

In the calculation formula of the above model, $F_{i j}$ represents the ecological niche of the factor $i$ belonged to the ecological unit $j ; S_{i j}$ and $P_{i j}$ represents the status and the tendency of the factor $i$ belonged to the ecological unit $j$; $S_{i j}+D_{i j} P_{i j}$ is called "the absolute niche"; $D_{i j}$ is the dimensionless conversion coefficient; $E_{j}$ represents the breadth of the ecological niche about the ecological unit $j ; C_{i j}$ represents the diversity of the factor $i$ belonged to the ecological unit $j ; \bar{N}$ represents the average breadth of the factor $i$ belonged to all of the ecological units; $m$ represents the number of the ecological units; $n$ represents the number of the factors belonged to the ecological unit [13]. The breadth of the ecological niche can be calculated by weighted average of gradual layering factor for the ecological unit including multi-layer factors. $i=1,2, \ldots, n, j=1,2, \ldots, m$.

\section{INDEX SYSTEMS ESTABLISHED AND BASIC DATA PROCESSED}

As a compound ecosystem composed by economic, scale and technology, the breadth of the ecological niche about the construction industry is decided by the multi-layer factors system. According to the objective, scientific, independent and comparable principles, this study selected three primary factors (i.e. economy, scale and technology) which reflected the status of the development of the construction industry. And then the primary factors were represented by a series of secondary factors basing on the representative, typical and available data. At last, we established a multi-factor index system about the quantitative calculation of the ecological niche for the regional construction industry. 
This paper collected the statistical data of 31 provinces in China from 2007 to 2012. Considering the influences of the inflation and the price changes, the selected data in different years were corrected according to the 2012 constant prices to enhance the accuracy and comparability. The Index F11, F12, F21 and F34 were corrected according to the price index for investment in fixed assets. The Index F13 and F14 were corrected according to the producer price index for industrial products. The Index F22 and F32 were corrected according to the purchasing price index for industrial products. The Index F23, F24, F31 and F33 needn't to be corrected, because they are not measured by money. All the essential data are derived from the "China Statistical Yearbook".

\section{RESULTS AND ANALYSIS OF THE QUANTITATIVE CALCULATION}

On the basis of the computational index factors about the ecological niche in the Table 1, the 2012 statistical data of the each factor were taken as the measurements of the "Status"; the average growth during the 2008 to 2012 of the each factor were taken as the measurements of the "Tendency". We took one year as the time rule, i.e. $D_{i j}=1$. Using the econometric model of the ecological niche to calculate each factor, we can get the ecological niche values of the primary factors, the integrated ecological niche and the diversity of the ecological niche. The details are shown in the Table 2.

Through the analysis of Table 2 , from the values and ranks of the integrated ecological niche, there are 11 provinces locate in the upstream, and their integrated ecological niche values are higher than the average value of the whole country (0.033258). These 11 provinces are Beijing, Tianjin, Hebei, Liaoning, Jiangsu, Zhejiang, Shandong, Henan, Hubei, Guangdong and Shaanxi respectively. It shows that these regions have a better development and a stronger competitiveness in the whole construction industry system in our country. For the rest of the 20 provinces, their breadths and ranks of the ecological niche are fare poorly in the ranking. They are at a disadvantageous position and have a weak competitiveness in the whole construction industry system. And their ecological niches need to improve urgently.

In the view of the values and ranks about the economic ecological niche, Jiangsu (0.106658), Zhejiang (0.083987) and Liaoning (0.070288) rank in the top 3 with the breadths which are more than twice of the average (0.033258). It shows that the eastern coastal regions have some advantages for the inputs and outputs of fixed assets in the national construction industry. In addition, the economic ecological niches of Shandong, Shaanxi, Gansu, Hubei and Beijing are relatively reasonable. The regions whose economic ecological niche is above the average are Guangdong, Sichuan and Henan. In the aspect of the scaled ecological niche, Jiangsu (0.125950), Zhejiang (0.094151) and Liaoning (0.072856) still rank in the top 3 with the breadths which are more than twice of the average (0.033258). It indicates that the inputs and outputs have a certain correlation with the degree of the scaled expansion in these 3 provinces. The scaled ecological niches of Henan, Shandong, Guangdong, Hubei and Hebei have a better performance. Fujian, Anhui and Sichuan are in the general level about the scale. The best regions of the technology ecological niche are Tianjin (0.097960), Jiangsu (0.067876) and Beijing (0.065174). The introduction and implementation of the new technology and equipment are apparently at the head of the class about the regional construction industry in our country. Furthermore, the technical ecological niches of Hebei, Hubei and Henan are relatively reasonable. Jilin, Yunnan, Liaoning, Hunan, Shanxi and Guangdong have been flat in the aspect of the technical ecological niche.

Table 1. The measurement index system about the ecological niche of the regional construction industry.

\begin{tabular}{|c|c|c|}
\hline Target Layer & Primary Factors & Secondary Factors \\
\hline \multirow{12}{*}{$\begin{array}{l}\text { E Ecological Niche of Regional } \\
\text { Construction Industry }\end{array}$} & \multirow{4}{*}{$\begin{array}{l}\text { F1 Economic Niche of Regional Construc- } \\
\text { tion Industry }\end{array}$} & $\begin{array}{l}\text { F11 Total Investment in Fixed Assets in the Whole Country of } \\
\text { Construction Industry }\end{array}$ \\
\hline & & F12 Gross Output Value of Construction \\
\hline & & F13 Total Revenue of Construction Enterprises \\
\hline & & F14 Total Profits of Construction Enterprises \\
\hline & \multirow{4}{*}{$\begin{array}{l}\text { F2 Scaled Niche of Regional Construction } \\
\text { Industry }\end{array}$} & F21 Total Investment in Construction in the Whole Country \\
\hline & & F22 Fixed Assets of Construction Enterprises \\
\hline & & F23 Number of Construction Enterprises \\
\hline & & F24 Number Of Employed Persons of Construction Enterprises \\
\hline & \multirow{4}{*}{$\begin{array}{l}\text { F3 Technical Niche of Regional Construc- } \\
\text { tion Industry }\end{array}$} & F31 Total Power Of Machinery and Equipment Owned \\
\hline & & F32 Value of Machines per Laborer \\
\hline & & F33 Power of Machines per Laborer \\
\hline & & F34 Overall Labor Productivity \\
\hline
\end{tabular}


Table 2. The ecological niche about national regional construction industry.

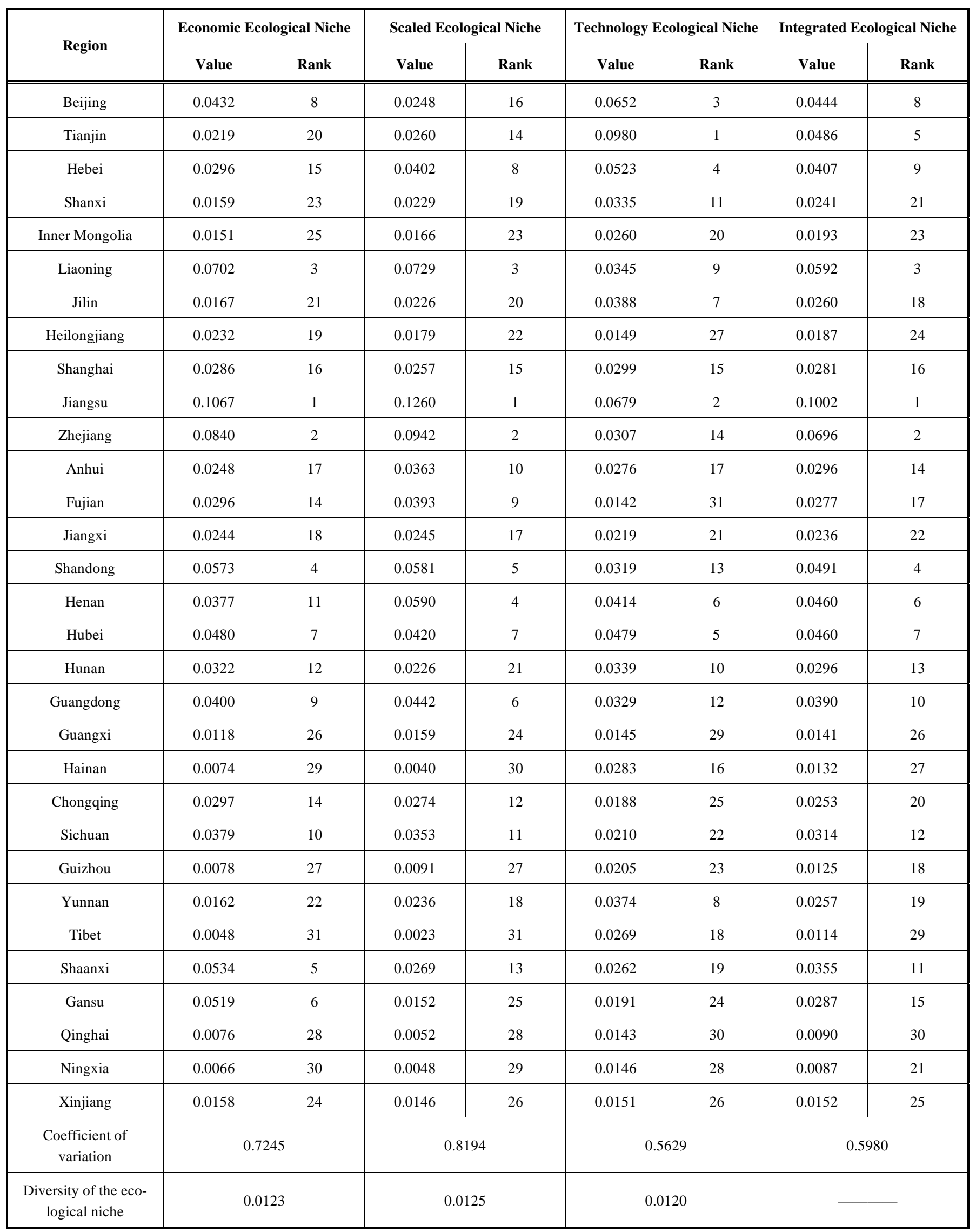


By calculating the coefficient of variation and the diversity of the ecological niche about each factor, it is found that the two values of the scaled ecological niche are the largest among the economic factors, scaled factors and technical factors, and the calculated values are 0.819395 and 0.012522 respectively. The second largest values of the coefficient of variation and the diversity of the ecological niche belonged to the economic ecological niche, and the calculated values are 0.724499 and 0.012324 respectively. The values of the technical ecological niche are the smallest with 0.562939 and 0.012038 . According to the coefficient of variation about the scaled ecological niche, the difference of the development scale is fairly large about the regional construction industry in our country. Meanwhile, the diversity of the ecological niche further confirms that the large difference of the scale is the main reason which decides the difference of the integrated ecological niche in the regional construction industry.

The status of the ecological niche factors about the regional construction industry is shown in Fig. (1). In the three factors determined the integrated ecological niche, the black portion represents the provinces whose three indicators are all above the average. The provinces that have two aboveaverage indicators are expressed in dark grey. The light gray areas means that the provinces which only have one aboveaverage indicators. The rest of the white parts show that the provinces have no indicator above the average. The provinces with the larger breadth mainly concentrated in eastern coastal and central regions. The representative provinces mainly include Liaoning, Beijing, Hebei, Shandong, Jiangsu and Zhejiang in the eastern coastal areas. And Henan and Hubei are the represents of the central regions. In addition, both Guangdong in the south and Sichuan in the west also have a relatively large breadth of the ecological niche. For the north, the west and the southwest, their breadth of the ecological niche are relatively narrow. It indicates these areas have a weak competitiveness.

\section{FOUND PROBLEMS AND COUNTERMEASURES}

The expansion of the ecological niche about the regional construction industry is mainly realized through adapting to the good ecological niche, exploiting the spare ecological niche, competing for the construction resources, balancing the ecological niche. The expansion is the driving force for the evolution of the regional construction development. Based on the ecological niche theory, this paper studied on the ecological niche of the regional construction industry in China. And then, some problems and countermeasures about the development of the regional construction industry were found. Specific content as follows:

Firstly, the industrial center of the Chinese construction development is still concentrated with the coastal and central areas after the rapid development since the reform and opening-up. While the development of the north, west and southwest is relatively backward. The eastern and coastal provinces have some advantages in the resources of the fixed assets investment and the scale social construction. Those provide many good conditions for the growth of the output, the increase of the profits and the expansion of the enterprise-scale. Due to the lack of the resources and the shortage of the construction in the northern, western and southwestern provinces, the development and the comprehensive competitive of the construction obviously appear to be the backward situation in these regions. It is suggested that basing on the good development situation of the eastern coastal and the central construction industry, the government should increase the radiant influence of these areas to promote the development of the regional construction industry surrounding them. Meanwhile, the construction and the development efforts of the northern, western and northwestern provinces should be strengthened. In these ways, the government can provide more opportunities and platforms for the development of the regional construction industry and improve the competitiveness in these areas.

Secondly, the economic and scaled ecological niche of Jiangsu, Zhejiang and Liaoning rank in the top 3 with breadths which are more than twice of the average (0.033258). At the same time, the technical ecological niche of Jiangsu also ranks in the second place. It indicates that the status and tendency of Jiangsu construction industry are very good and its competitiveness and radiation are the strongest. The situations of the regional construction development in Liaoning, Henan, Hubei and Guangdong are also optimistic. The rest of the provinces have some certain inadequacies in different aspects. For Hebei, Tianjin, Shanxi, Jilin, Anhui, Fujian, Hunan and Yunnan, these provinces should enhance the economic ecological niche by increasing the investment in fixed assets and improving the construction output value and profit margins. The regional construction industries in Beijing, Tianjin, Shanxi, Jilin, Hunan, Yunnan, Shaanxi and Gansu should adopt some measures to encourage the construction enterprises to expand their scale, so that it can provide the basic conditions for the enterprises to get large-scale projects and gain more revenues. In Zhejiang, Anhui, Fujian, Sichuan, Shaanxi and Gansu, the efforts on introducing the new construction technology need to be improved, and the assembly and utilization ratio also need to be strengthened. It can make up for the backward in the development and competitiveness about the regional construction industry in these areas. In addition, the provinces that need to enhance in all three aspects, i.e. economy, scale and technology, are Inner Mongolia, Heilongjiang, Shanghai, Jiangxi, Guangxi, Hainan, Chongqing, Guizhou, Tibet, Qinghai, Ningxia and Xinjiang. These areas should make full use of the radiant influence of the surrounding developed areas to promote the reform and the adjustment on its industrial policy and structure.

Finally, on the view of the coefficient of variation and the diversity of the ecological niche about each factor, it fully shows that the rapid development of national regional construction industry depended on the expansion of the scale and the economy in recent years, not by improving the level of the management and technology. Meanwhile, this expansion of the scale and the economy is not balanced in the eastern coastal, central, northern and western regions, it causes that the construction developmental level in the eastern coastal and the central regions are better than in the other regions. The overall technical ecological niches are relatively low. It shows that the management and the technology are still at a low level on national regional construction. This article suggests that in the aspect of formulating the measures about the development and the reform, the government 


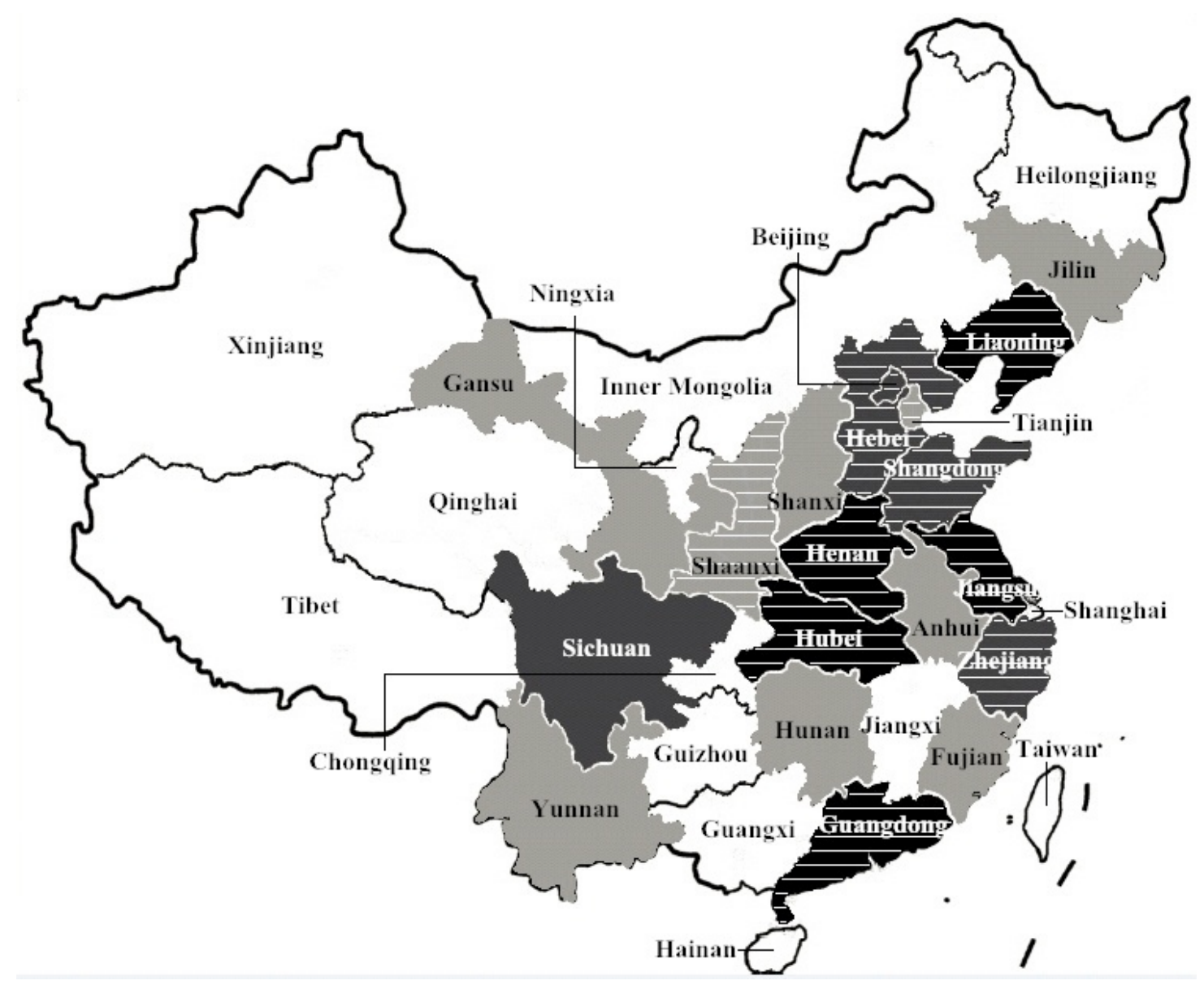

Fig. (1). Factors of the ecological niche for national regional construction industry.

should put effort in developing and building the fixed assets and fundamentally promote the construction development in the remote areas such as the north and the west, etc. And they also should strengthen the $R \& D$ and the spreading of the technological advanced achievement, further promote the transformation of the construction industry from the "extensive" to the "intensive", and improve the labor productivity.

\section{CONCLUSION}

This paper introduces the ecological niche theory into the evaluation field of the construction development, and observes the development situation of national regional construction industry in recent years from a new perspective. By using the quantitative model of the ecological niche and selecting the related indicators, it calculates and analyzes the ecological niche of the regional construction industry in China. And then some suggestions and measures about the future development of the regional construction industry are given. But the research on the ecological niche of the construction industry is still in the preliminary exploratory stage. In particular, the selection and the calculation of the factors and the indicators still need to be further perfected and improved.

\section{CONFLICT OF INTEREST}

The authors confirm that this article content has no conflict of interest.

\section{ACKNOWLEDGEMENTS}

Declared none.

\section{REFERENCES}

[1] J.J. Tang, Z.X. Li, W.Z. Liang, and T.S. Zhao, "Present situation analysis and development trend forecast of construction industry", Journal of Civil Engineering and Management, vol. 29, pp. 84-88, December 2012.

[2] Y.X. Gu, X. Wang, and Q.Y. Ying, "Current status development direction of China construction industry", Construction Quality, vol. 31, pp. 3-8, January 2012.

[3] Y.S. Wang, and Y. Zhang, "Assessment and analysis of the productive technical efficiency of the construction industry in China", Journal of South China University of Technology (Natural Science), vol. 28, pp. 96-100, October 1985.

[4] Y.S. Wang, W.J. Zhang, and Y. Zhang, "Assessment and analysis of the productive technical efficiency of the construction industry in China", Construction Economy, vol. 368, pp. 101-104, June 2013.

[5] J. Du, "The development of the national construction industry came into a turning point", Science \& Technology Information, vol. 32, pp. 231-232, November 2007.

[6] Q. Chen, X.D. Li, and C. Wu, "Assessment of construction enterprise development based on fuzzy dynamic clustering analysis", Journal of Engineering Management, vol. 25, pp. 607-611, December 2011.

[7] C. Zhuang, and J.R. Ye, "Analysis about development of the regional construction industry based on the factor analysis method", Knowledge Economy, vol. 20, pp. 127-127, October 2012.

[8] B. Wen, Y.S. Wang, and Y. Zhang, "Empirical study on the developmental differences of the chinese construction industry", Construction Economy, vol. 3, pp. 8-11, March 2009. 
[9] X.Q. Wang, H. Pan, and B.S. Liu, "Study on Evaluation of competitiveness of chinese regional construction industry based on cloud model", Journal of Shanxi Finance and Economics University, vol. 34, pp. 55-66, July 2012.

[10] B.S. Liu, T.F. Huo, X.Q. Wang, and Z.Y. Yang, "DEA Model with SEM Constraint Cone and Its Application in construction efficiency", Transactions of Beijing Institute of Technology, vol. 32, pp. 865-870, August 2012.
[11] Y.H. Chiang, B.S. Tang, W.Y. Leung, and Z.Y. Yang, "Market structure of the construction industry in Hong Kong", Construction Management and Economics, vol. 19, pp. 591-599, July 2001.

[12] G. Ofori. "International contractors and structural changes in host country construction: Case of Singapore". Engineering Construction and Architectural Management, vol. 3, pp. 271-288, February 1996.

[13] C.Q. Zhu, "The Niche Ecostate-Ecorole Theory and Expansion Hypothesis", Acta Ecologica Sinica, vol. 17, pp. 324-332, May 1997.

(C) Wang et al.; Licensee Bentham Open.

This is an open access article licensed under the terms of the Creative Commons Attribution Non-Commercial License (http://creativecommons.org/licenses/by-nc/3.0/) which permits unrestricted, non-commercial use, distribution and reproduction in any medium, provided the work is properly cited. 